\title{
Modification of combustion behaviour and NO emissions by coal blending
}

\author{
F. Rubiera*, A. Arenillas, B. Arias and J.J. Pis \\ Department of Energy and Environment. Instituto Nacional del Carbon, CSIC. Apartado 73. \\ 33080 Oviedo (Spain)
}

\begin{abstract}
Combustion profiles determined by TGA and experiments in a laminar entrained flow reactor (EFR) were used in this work to assess the relative combustion reactivities of different rank coals and their binary coal blends. The combustion behaviour of coal blends in TGA was greatly influenced by coal rank and the proportion of each component in the blend. Higher volatile coals exerted more influence in the low temperature region and less reactive coals in the char combustion zone. The results in the EFR indicated that coal blends burnout and NO emissions show additivity in the case of similar nature coals. When one of the components was a high rank coal, the burnout of the blend exhibited, in some cases, positive synergistic effects, while a clear deviation from linearity was found in NO emissions.
\end{abstract}

Keywords: Coal blends; Combustibility; Entrained flow reactor; NO emissions

\section{Introduction}

Coal blending is becoming a common practice in large coal combustion plants, which utilise low-cost imported coals for blending with local coals. Some of the properties of a blend such as calorific value, volatile matter and ash content, can be determined from the weighed average of the properties of the individual coals in the blend [1]. Similarly, some aspects of the combustion behaviour of blended coals in power stations are known, and can be determined reasonably well from knowledge of the properties of the component coals in the blend and their respective mass fractions [2]. However, the combustion characteristics of a coal blend (i.e., ignition behaviour, burnout, unburned carbon, NOx emissions) cannot always be predicted as a linear combination of the properties of each component.

While several authors have made use of thermogravimetry [3, 4] and drop tube furnaces $[5,6]$ for the combustion of coal blends, no general consensus has been reached on the interaction between component coals. Moreover, while some authors state that high-volatile coals improve carbon burnout, ignition and flame stability in blends with higher rank coals [7], other studies have reported a decrease in the overall burnout of the blend in comparison to that expected from the properties of the blend [8]. 
The main objective of this work was to study the possible modifications in combustibility behaviour, carbon burnout and NO emissions produced by blending coals of different origin and rank by means of temperature-programmed combustion tests in a thermogravimetric analyser along with tests in a laminar entrained flow reactor.

\section{Experimental}

Six coals of different rank, ranging from high volatile bituminous to anthracite, were used and their main characteristics are shown in Table 1. The individual coals were ground to minus $150 \mu \mathrm{m}$ and mixed to generate binary blends. The combustibility characteristics of the coals and their blends was evaluated by means of temperature-programmed combustion tests (TPC) [9]. In the TPC tests a sample mass of approximately $5 \mathrm{mg}$ was placed in the sample crucible of a TGA, and the temperature was increased to $1000{ }^{\circ} \mathrm{C}$ at $15{ }^{\circ} \mathrm{C} \mathrm{min}^{-1}$ in an air flow of 50 $\mathrm{mL} \mathrm{min}^{-1}$. A laminar entrained flow reactor (EFR) of $4 \mathrm{~cm}$ i.d. and $200 \mathrm{~cm}$ length was also employed to study the burnout and NO emissions of the samples at very different conditions (i.e., higher heating rates, $10^{4} \mathrm{~K} \mathrm{~s}^{-1}$, and shorter residence times, in the order of seconds) to those in the TGA. Interactive effects can be obtained in this equipment by using sufficiently high coal mass loadings. Thus group combustion behaviour (change in burning characteristics due to collective behaviour of a large number of particles) rather than single particle combustion applies $[10,11]$. In the EFR tests, coal feed rates in the order of $1 \mathrm{~g} \mathrm{~min}^{-1}$ were employed.

\section{Results and discussion}

Temperature-programmed combustion profiles

The results obtained from the combustion tests in the TGA showed clear differences in the combustibility characteristics of the blends. This different behaviour was dependent on the rank and proportion of the individual components in the blends. When bituminous coals such as GU and FI were mixed (Figure 1), it was observed that at low temperatures, in the zone of volatiles and initial char combustion, the DTG profiles of the blends were situated between those of the individual coals. It was also evident that the higher volatile content coal in the blend exerted more influence on the initial reactive characteristics of the blends. In the high temperature region, ascribed to the zone after the peak temperature of the higher volatile coal, the burning characteristics of the blends at 25 and 50wt\% of coal GU, were markedly closer to the more reactive coal. At higher temperatures $\left(600-610^{\circ} \mathrm{C}\right)$, there was a displacement of the curves towards that of the higher rank, less reactive coal in the blend. In the case of the 
blend comprising a higher percentage (75wt\%) of coal FI, the behaviour is clearly dominated by the less reactive coal, FI, as can be seen in Figure 1.

Other blends made up from bituminous coals showed similar behaviour to that presented above, but differences were attained with varying proportions of the component coals. For instance, the GU-DI blend with $25 \mathrm{wt} \%$ of coal GU presented the interactive effect (i.e., combustion profile approaching that of the more reactive coal) in the high temperature region, while the curves of the blends with 50 and $75 w t \%$ showed a behaviour that could be predicted from that of the individual coals.

For blends of very different rank coals (e.g., bituminous with anthracite or semianthracite) two distinct peaks were systematically found for the $50 \mathrm{wt} \%$ blends, indicating that the two coals burn independently in accordance with the results of other authors [4, 12]. However, when blends at other percentages were considered no clear distinction between two peaks was encountered, as can be seen in Figure 2 for blends of an anthracite, GI, with coal FI. Even the blend with $75 \mathrm{wt} \%$ of coal FI, is influenced more by the higher reactive coal, at least up to a temperature of $650{ }^{\circ} \mathrm{C}$, corresponding to $95 \%$ burnoff.

\section{Combustion of coal blends in Laminar Entrained Flow Reactor (EFR)}

Despite it has been stated that TGA techniques are quite useful for predicting the relative combustion characteristics of coals at large scale $[13,14]$, the conditions in this equipment are very different to those encountered in industrial boilers. Entrained flow reactors provide experimental conditions closer to real firing systems than TGA, at least in terms of heating rates, residence times and flame conditions [7].

The results obtained in the EFR for coal blends from different rank coals at $1000{ }^{\circ} \mathrm{C}$, are given in Table 2. The blends from similar rank coals, GU-FI, showed a remarkable linearity at the two experimental conditions with regard to burnout, in agreement with the results of other authors $[5,8]$. The same behaviour was attained in the case of NO emissions. For blends of very different rank coals, CA-GI and GU-HV, the burnout of the blends was fairly predictable at high percentages of the higher rank coal. However, at the lowest percentage (25\%) of the lower rank coal in the blends there was a trend of increasing burnout, with slight positive deviations from the weighed mean predicted burnout. Although the coals were blended over the whole range of percentages, in real industrial conditions only small proportions of one coal would be mixed with another coal of very different rank. The results of this work, therefore, point to a better overall burnout of the blend if low proportions of a high volatile coal are added. 
Regarding NO emissions, a clearly, non-additive behaviour was observed. There was an increase in the NO generated as the proportion of high volatile bituminous coals in the blends increased. These results can be explained taking into account the fact that in these blends (CA-GI and GU-HV), the volatiles are in a lower concentration than when CA or GU are burned alone, and less oxygen is needed for the volatiles combustion. Thus the conversion efficiency of volatile-N to NO under a higher oxygen partial pressure may increase. The sequential burning of the char also takes place in a higher oxygen atmosphere, giving more NO. Thus it seems that variation in the oxygen available had a significant influence on the behaviour of the blends.

The TPC tests of the chars obtained in the EFR showed that there was a preferential burning of the high volatile coals in the blends. This can be seen from the data plotted in Arrhenius form in Figure 3 for blend CA-GI (1 second residence time, 0\% excess air). The reactivities of the chars from the blends at 50 and $75 w t \%$ of GI were closer to those of char GI. Figure 3 also reflects a linear increase in activation energy as the degree of burnout increases.

\section{Conclusions}

The use of combustion profiles determined by TGA showed the presence of interactive effects during the burning of coal blends. These effects were dependent on the rank and proportion of the individual components in the blends. In the zone of volatiles release and early stage of char gasification, the reactivity of the blend was influenced more by the higher reactive coal. In the later stage of char combustion, the reactivity of the blends is dominated by the less reactive, higher rank coal.

When using a laminar entrained flow reactor, non-additive negative effects were attained in the case of NO emissions from blends of dissimilar rank coals, although higher burnout degrees were achieved at low proportions of high reactive coals. This effect can be attributed to an enhancement in the combustion behaviour of the lower rank coals as a consequence of the increased oxygen availability.

\section{Acknowledgements}

Work carried out with a financial grant from the European Coal and Steel Community (Project 7220-PR-071). 


\section{References}

1. J. Hass, M. Tamura and R. Weber, Fuel, 80 (2001) 1317.

2. J.P. Smart and T. Nakamura, J. Institute Energy, 66 (1993) 99.

3. W. Pan and Y. Gan, Thermochimica Acta, 180 (1991) 203.

4. P. Ciambelli, M. D’Amore, V. Palma, P. Russo and S. Vaccaro, 4th Int. Conf. on Technologies and Combustion for a Clean Environment, Lisbon, 1997, Vol. I, p. 2.3.

5. V. Artos and A.W. Scaroni, Fuel, 72 (1993) 927.

6. J. Qiu, F. Li, H. Zeng, B. Yao and Y. Ma, Combust. Sci. Tech., 157 (2000) 167.

7. S. Su, J.H. Pohl, D. Holcombe and J.A. Hart, Prog. Energy Comb. Sci., 27 (2001) 75.

8. T. Beeley, P. Cahill, G. Riley, P. Stephenson, M. Lewitt and M. Whitehouse, Report no. Coal R177, DTI/Pub URN 001509, March 2000.

9. F. Rubiera, A. Arenillas, E. Fuente, N. Miles and J.J. Pis, Powder Technology, 105 (1999) 351.

10. K. Annamalai and S.C. Ramalingan, Combustion \& Flame, 70 (1987) 307.

11. B. R. Stanmore, Y.C. Choi, R. Gadiou, O. Charon and P. Gilot, Combust. Sci. Tech., 159 (2000) 237.

12. J.W. Cumming, Thermochimica Acta, 155 (1989) 151.

13. S.V. Pisupati and A.W. Scaroni, Proceedings ICCS’97, DGMK, 1997, Vol. II, p. 1151.

14. P. Davini, P. Ghetti, L. Bonfanti and G. de Michele, Fuel, 75 (1996) 1083. 
Table 1. Main characteristics of the coals used.

\begin{tabular}{lcccccc}
\hline COAL & CA & GU & FI & DI & HV & GI \\
\hline Proximate Analysis & & & & & & \\
\hline Ash (wt \%, db) & 7.6 & 5.0 & 7.8 & 5.0 & 9.4 & 9.3 \\
V.M. (wt \%, db) & 37.8 & 38.5 & 17.9 & 13.7 & 9.1 & 3.8 \\
\hline Petrographic Analysis & & & & & & \\
\hline Vitrinite (vol \%, daf) & 89.3 & 78.4 & 94.5 & 84.8 & 94.7 & 97.3 \\
Exinite (vol \%, daf) & 5.4 & 3.3 & 0 & 0 & 0 & 0 \\
Inertinite (vol \%, daf) & 5.3 & 18.3 & 5.5 & 15.2 & 5.3 & 2.7 \\
Mean Random Reflectance & 0.74 & 0.67 & 1.55 & 1.77 & 2.24 & 4.15 \\
(\%) & & & & & & \\
\hline
\end{tabular}

Table 2. Comparison between experimental and theoretical (calculated assuming linear behaviour) burnout and NO emissions of coal blends in the laminar entrained flow reactor $\left(T=1000^{\circ} \mathrm{C}\right)$.

\begin{tabular}{|c|c|c|c|c|c|c|c|}
\hline Blend & $W t \%^{a}$ & $\begin{array}{c}\text { Residence } \\
\text { time (s) }\end{array}$ & $\begin{array}{l}\text { Excess } \\
\operatorname{air}(\%)\end{array}$ & $\begin{array}{l}\text { Experimental } \\
\text { Burnout (\%) }\end{array}$ & $\begin{array}{l}\text { Theoretical } \\
\text { Burnout (\%) }\end{array}$ & $\begin{array}{l}\text { Experimental } \\
\text { NO (ppm) }\end{array}$ & $\begin{array}{l}\text { Theoretical } \\
\text { NO (ppm) }\end{array}$ \\
\hline \multirow{7}{*}{$C A-(G I)$} & 0 & & & 74.9 & 74.9 & 276 & 276 \\
\hline & 25 & & & 70.9 & 67.2 & 299 & 256 \\
\hline & 50 & 1 & 0 & 60.2 & 59.4 & 307 & 236 \\
\hline & 75 & & & 54.1 & 51.7 & 306 & 216 \\
\hline & 100 & & & 43.9 & 43.9 & 196 & 196 \\
\hline & 0 & & & 93.0 & 93.0 & 322 & 322 \\
\hline & 25 & & & 86.2 & 87.0 & 348 & 304 \\
\hline$C A-(G I)$ & 50 & 1.3 & 30 & 81.2 & 81.0 & 335 & 286 \\
\hline
\end{tabular}




\begin{tabular}{|c|c|c|c|c|c|c|c|}
\hline & 75 & & & 77.1 & 74.9 & 324 & 267 \\
\hline & 100 & & & 68.9 & 68.9 & 249 & 249 \\
\hline \multirow{5}{*}{$G U-(F I)$} & 0 & & & 74.4 & 74.4 & 223 & 223 \\
\hline & 25 & & & 75.1 & 75.9 & 254 & 254 \\
\hline & 50 & 1 & 0 & 76.6 & 77.4 & 284 & 286 \\
\hline & 75 & & & 76.5 & 78.8 & 310 & 317 \\
\hline & 100 & & & 80.3 & 80.3 & 348 & 348 \\
\hline \multirow{5}{*}{$G U-(F I)$} & 0 & & & 92.9 & 92.9 & 369 & 369 \\
\hline & 25 & & & 93.0 & 94.1 & 443 & 420 \\
\hline & 50 & 1.3 & 30 & 95.5 & 95.3 & 502 & 471 \\
\hline & 75 & & & 97.0 & 96.5 & 531 & 522 \\
\hline & 100 & & & 97.7 & 97.7 & 573 & 573 \\
\hline \multirow{5}{*}{$G U-(H V)$} & 0 & & & 92.9 & 92.9 & 369 & 337 \\
\hline & 25 & & & 85.8 & 86.7 & 386 & 353 \\
\hline & 50 & 1.3 & 30 & 82.1 & 80.6 & 417 & 368 \\
\hline & 75 & & & 80.6 & 74.4 & 446 & 384 \\
\hline & 100 & & & 68.2 & 68.2 & 399 & 399 \\
\hline
\end{tabular}

${ }^{a}$ Percentage corresponding to the coal in brackets in the first column. 


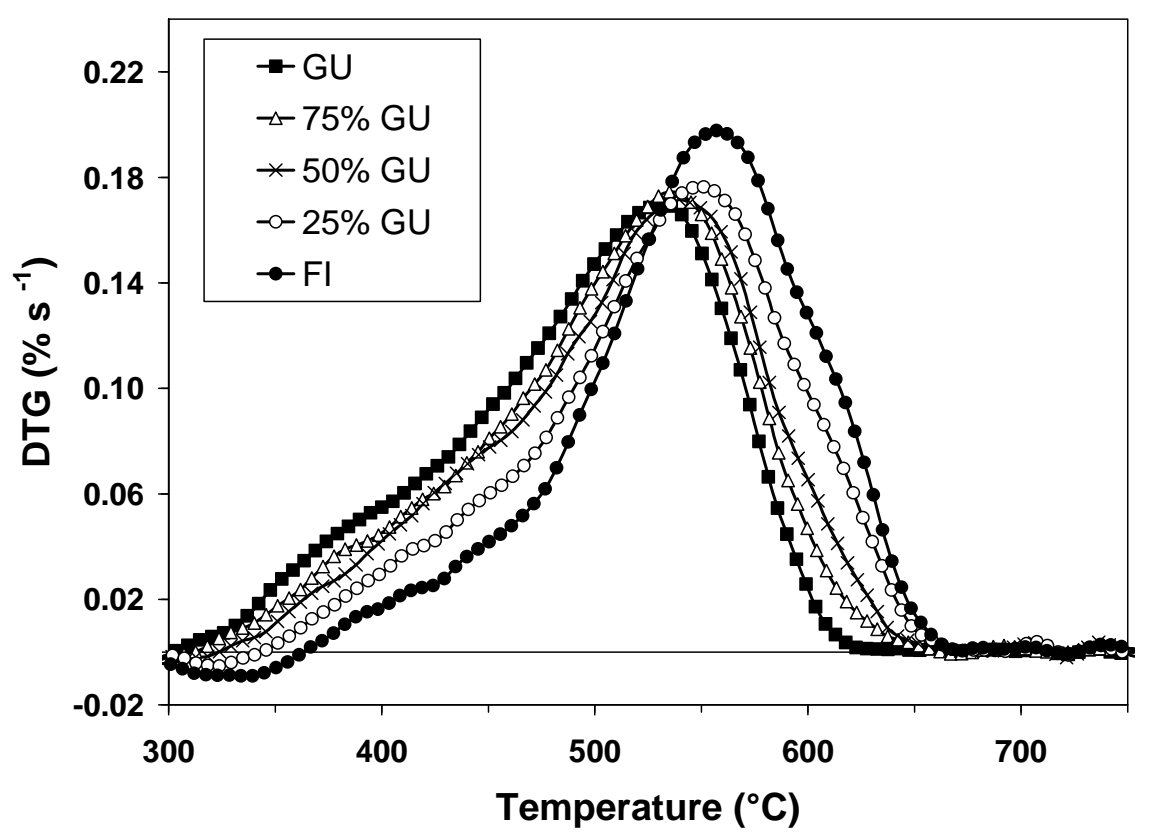

Figure 1.

Modification of combustion behaviour and NO emissions by coal blending F. Rubiera et al. 


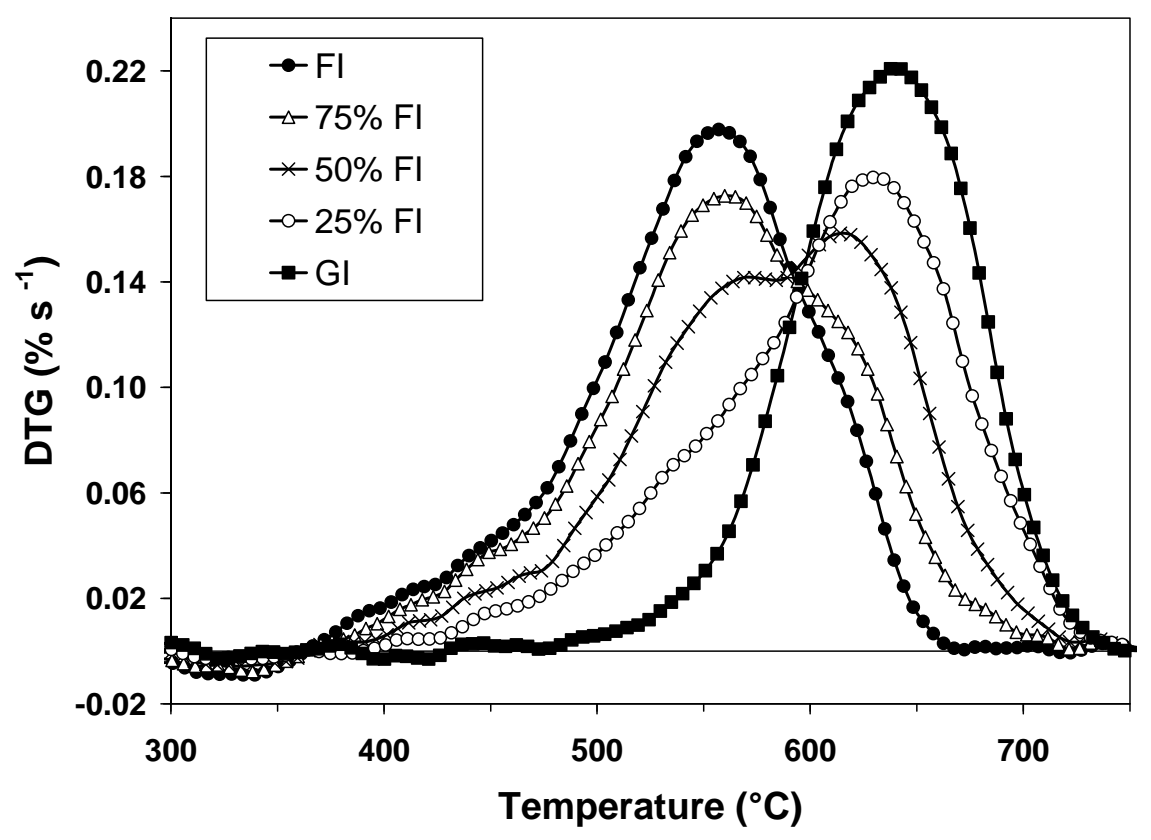

Figure 2.

Modification of combustion behaviour and NO emissions by coal blending F. Rubiera et al. 


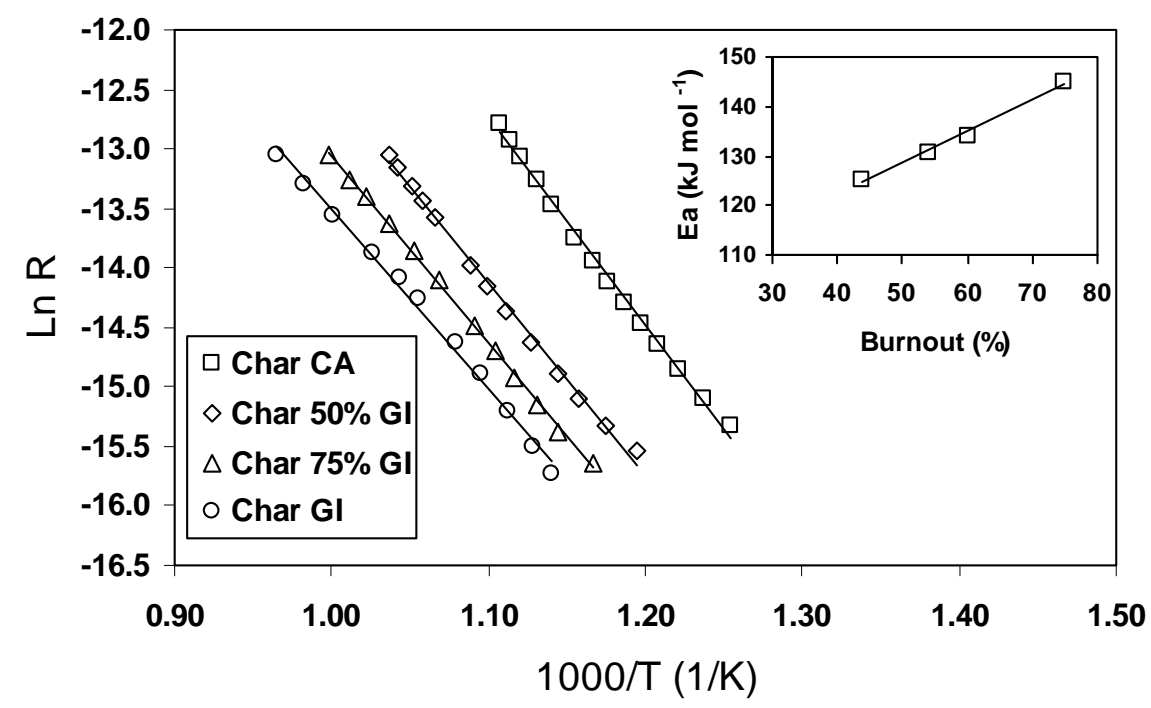

Figure 3.

Modification of combustion behaviour and NO emissions by coal blending

F. Rubiera et al. 